\title{
NATURAL CONVECTION HEAT TRANSFER IN TWO-SQUARE DUCT ANNULI FILLED WITH A NANOFLUID
}

\author{
N.A. Bakar ${ }^{1, a}$, F. Aman 2,b ${ }^{2, M}$. Mohamad ${ }^{3, c}$ and R. Roslan ${ }^{4, d}$ \\ ${ }^{1,2,3,4}$ Faculty of Science, Technology and Human Development, Universiti Tun Hussein Onn, \\ 86400 Parit Raja, Johor, Malaysia. \\ a*hw120019@siswa.uthm.edu.my, bfazlina@uthm.edu.my, 'cmahathir@uthm.edu.my, \\ drozaini@uthm.edu.my
}

Keywords: Annulus, finite difference, natural convection, nanofluid, square duct.

\begin{abstract}
The problem of natural convection fluid flow and heat transfer of $\mathrm{TiO}_{2}$-water nanofluid inside of two differentially-heated square ducts is analysed numerically by finite difference method. The outer duct is maintained at a constant temperature $T_{c}$, while the inner duct is kept at higher constant temperature $T_{h}$. The effect of the Rayleigh number, $R a$ and the nanoparticle volume fraction, $\varphi$ on the heat transfer and Nusselt number, $N u$ are investigated and compared to previous study.
\end{abstract}

\section{Introduction}

Natural convection heat transfer and fluid flow of nanofluid in enclosed cavities has received considerable interest because of the advantages and due to its importance in engineering applications, including electronics cooling devices, heat exchanger, electric machinery and solar energy collector [1]. [2] is the first who added metallic nanoparticles for examples copper $(\mathrm{Cu})$ and aluminium oxide $\left(\mathrm{Al}_{2} \mathrm{O}_{3}\right)$ to based fluid that is water and called the mixture as nanofluid. By definition, natural convection is the process of heat transfer through fluid whether it is air, water or any type of fluid [3]. The application of nanofluids on heat transfer has been investigated by many researchers and it was summarized by [4,5]. They concluded that the enhancement of heat transfer increases with nanofluids. Natural convection in a vertical rectangular cavity filled with $\mathrm{Cu}$-water nanofluid was investigated numerically by [6]. They indicated an increment in heat transfer by increasing $\boldsymbol{\varphi}$ at all Grashof numbers. Subsequent investigation was conducted by [7], to enhance natural convection heat transfer in a rectangular enclosure. They conducted a numerical study using Khanafer's model and found out that $\boldsymbol{\varphi}$ cause an increases in the average heat transfer. [8] investigated numerically the effects of Prandtl number, Pr in order to study the impact of thermal boundary condition in square cavity. They discovered that the nonuniform heating of the bottom wall led to a higher heat transfer rate than the uniform heating. [9, 10] investigated natural convection heat transfer in partially heated cavity containing different nanofluids. They showed that the flow and temperature fields are depending on the length and location of the heat source. [11] examined the natural convection heat transfer performance of nanofluids in an inclined cavity while [12] studied the heat transfer performance of various buoyancy-driven nanofluids in a differentially heated tilted cavity. $[13,14,15]$ also found out heat transfer enhances with addition of nanoparticle in the base fluid. Earlier, [16] studied natural convection in a vertical square cavity with heat conducting body that is placed at the center in order to investigate the effect of heat conducting body on the heat transfer process in the cavity. They found that the heat transfer across the cavity enhanced by a body with thermal conductivity ratio less that unity. Then, [17] studied the natural convection around a tilted heated cylinder placed inside a cavity with cold side walls. Subsequently, [18] analyzed conjugate natural convection in an inclined square cavity with a conducting centered block. The annulus is filled with nanofluid. They concluded that nanofluid enhances the heat transfer performance and that the length of the centered block affects the heat transfer rate. [19] studied theoretically the convective heat transfer in a differentially heated square cavity filled with nanofluids with an inner rotating cylinder. They found that maximum heat transfers are obtained at 
a high nanoparticle concentration, a slow positive rotation and a moderate size cylinder located in the center of the cavity. Recently, [20] studied the problem of unsteady natural convection induced by a temperature difference between a cold outer square cavity and a hot inner circular cylinder. The cylinder temperature is assumed to vary sinusoidally with time. Meanwhile, [21] studied the natural convection in a differentially heated square cavity with an adiabatic square block at the center. However, [22] studied the natural convection in a square duct where the outer square is maintained at a constant temperature while the inner square is kept at a higher constant temperature. They solved the governing equation using the finite volume method. Motivated by the study of [22], the present study follows closely the work by [22]. However, the governing equations are solved using finite difference method.

\section{Mathematical modelling}

The physical configuration is as shown in Fig. 1(a). Each side of the inner square are denoted by $l$, while the outer square are denoted by $L$. Both squares are maintained at different constant temperatures of $T_{h}$ and $T_{c}$, where $T_{h}>T_{c}$. The space between the two squares is filled with $\mathrm{TiO}_{2^{-}}$ water nanofluid. It is considered that the nanofluid is Newtonian, laminar and incompressible. The nanoparticles are presumed to be in thermal equilibrium with the base fluid and there is no slip between them. The thermophysical properties of the base fluid and nanoparticles can be found in [22]. The thermophysical properties of the nanofluid are assumed to be constant with the exception of the density which varies according to the Boussinesq approximation [23]. The non-dimensional governing equations are given as follows:

$$
\begin{aligned}
& \frac{\partial U}{\partial X}+\frac{\partial V}{\partial Y}=0 \\
& U \frac{\partial U}{\partial X}+V \frac{\partial U}{\partial Y}=-\frac{\partial P}{\partial X}+\frac{\mu_{n f}}{\rho_{n f}}\left(\frac{\partial^{2} U}{\partial X^{2}}+\frac{\partial^{2} U}{\partial X^{2}}\right) \\
& U \frac{\partial V}{\partial X}+V \frac{\partial V}{\partial Y}=-\frac{\partial P}{\partial Y}+\frac{\mu_{n f}}{\rho_{n f} \alpha_{f}}\left(\frac{\partial^{2} V}{\partial X^{2}}+\frac{\partial^{2} V}{\partial Y^{2}}\right)+\frac{(\rho \beta)_{n f}}{\rho_{n f} \beta_{f}} R a \operatorname{Pr} \theta \\
& U \frac{\partial \theta}{\partial X}+v \frac{\partial \theta}{\partial Y}=\frac{\alpha_{n f}}{\alpha_{f}}\left(\frac{\partial^{2} \theta}{\partial X^{2}}+\frac{\partial^{2} \theta}{\partial Y^{2}}\right)
\end{aligned}
$$

where all the physical quantities are defined in the nomenclature. Eqs. (1)-(4) need to be solved subject to the boundary conditions $U=V=0, \theta=1$ on the inner square; $\theta=0$ on the outer square. Here, the dimensionless parameters used in the analysis are $X=\frac{x}{L}, Y=\frac{y}{L}, U=\frac{u L}{\alpha_{f}}$, $V=\frac{v L}{\alpha_{f}}, P=\frac{p L^{2}}{\rho_{n f} \alpha_{f}{ }^{2}}, \quad \theta=\frac{T-T_{c}}{T_{h}-T_{c}}, R a=\frac{g \beta_{f} \Delta T L^{3}}{\alpha_{f} v_{f}} \quad$ and $\operatorname{Pr}=\frac{v_{f}}{\alpha_{f}}$. The density formulation, $\rho_{n f}=$ $(1-\varphi) \rho_{f}+\varphi \rho_{s}$, the heat capacity, $\left(\rho C_{p}\right)_{n f}=(1-\varphi)\left(\rho C_{p}\right)_{f}+\varphi\left(\rho C_{p}\right)_{s}$, the thermal expansion coefficient, $(\rho \beta)_{n f}=(1-\varphi)(\rho \beta)_{f}+\varphi(\rho \beta)_{s}$, the effective viscosity, $\mu_{n f}=\mu_{f}\left(199.21 \varphi^{2}+\right.$ $4.62 \varphi+1.0)$ the thermal conductivity, $k_{n f}=k_{f}\left(125.62 \varphi^{2}+4.82 \varphi+1.0\right)$ and the thermal diffusivity of the nanofluid, $\alpha_{n f}=\frac{k_{n f}}{\left(\rho C_{p}\right)_{n f}} . N u$ of the outer square based on the height or width is expressed as $-\left.\left(\frac{k_{n f}}{k_{f}}\right) \frac{\partial \theta}{\partial X}\right|_{\text {wall }}$.

\section{Computational Methodology}

The finite difference formulation together with Gauss Seidel iteration method are utilised to solve the problem. The convection-diffusion terms are discretized by backward and central difference 
formula and modelled in FORTRAN. $N u$ of the present study is compared to [22] for three different $R a$ and $\varphi$. It is found that the present results are in good agreement with [22]. Fig. 1(b) shows the average $N u$ of the cold square generally increases with the increasing of $R a$. For $R a=10^{3}$, five different grids, namely $20 \times 20,40 \times 40,80 \times 80,100 \times 100,120 \times 120$ result the average $N u$ given as $2.7500,2.4500,2.2625,2.2000,2.1250$, respectively. Therefore we chose $80 \times 80$ as independent grid. The convergence criterion for $U, V$ and $\theta$ are calculated using $\frac{\sum_{j=1}^{m} \sum_{i=1}^{n}\left|\zeta_{i, j}^{k+1}-\zeta_{i, j}^{k}\right|}{\sum_{j=1}^{m} \sum_{i=1}^{n}\left|\zeta_{i, j}^{k+1}\right|} \leq 10^{4}$, where $m$ and $n$ are the number grid points in $x$ - and $y$-directions respectively, $\zeta$ is any of the computed field variables and $k$ is the iteration number.

\section{Result and Discussions}

The results discussed here for a range of $R a=\left[10^{3}, 10^{5}\right]$ and $\varphi=0,0.02,0.04$. However, this paper is limited to discuss the isotherms only. Fig. 2 shows the isotherms in the annulus for different $R a$ and $\varphi$. For $R a=10^{3}$ and $10^{4}$, they are in some ways, evenly distributed within the entire annulus. This demonstrated a conduction-dominated heat transfer regime. For $R a=10^{5}$, still show a conduction-dominated heat transfer regime except that in its top part. The fluid in the bottom portion of the annulus is relatively stagnant and stays colder. The fluid near the inner square has a lower density than that near the outer square. Thus, the fluid near the surface of inner square moves upward while the relatively heavy fluid moves downward. Moreover, it is observed that the isotherms above the inner square become evenly distributed with the increasing nanoparticles.

\section{Conclusions}

The steady state two-dimensional natural convection of nanofluid within two square duct annuli is numerically studied in this paper. The inner duct is heated and kept at constant temperature while the outer square is cold and kept at constant temperature. The finite difference method is implemented to solve the governing equations. Isotherms as well as the $N u$ are presented graphically for different value of parametric study. The result in general show that at low Rayleigh numbers, conduction dominates the heat transfer process and a relatively weak heat transfer is consequently obtained. At higher $R a$, however, the strength of buoyant flow circulation increases and an improvement in heat transfer is achieved. Overall, comparison of present study with the one from the open literature shows very good agreement. This shows that finite difference method could also be used to solve such problem. Nevertheless, utilising finite difference method together with Gauss Seidel iteration method has limited the calculation where when $R a>10^{5}$ computation failed.

(a)

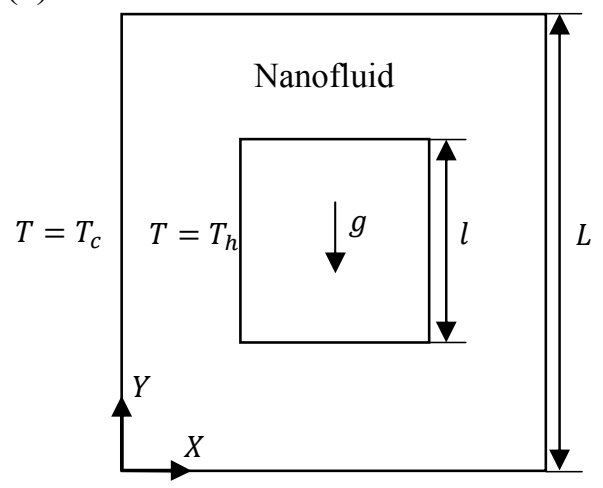

(b)

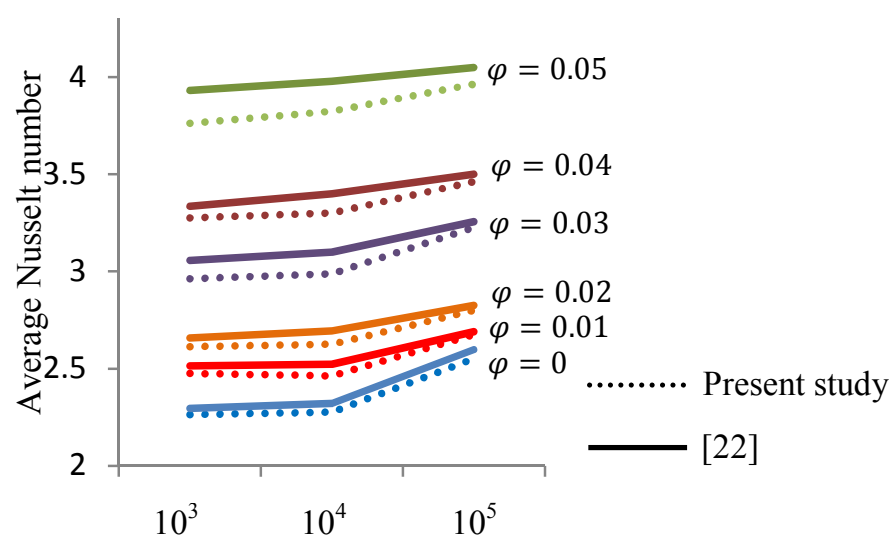

Figure 1: (a) Schematic view of the considered cavity in the present study. (b): Average Nusselt number variation for the outer square. 


\section{Nomenclature}

\begin{tabular}{|clcl|}
\hline$C_{p}$ & Heat capacity, $\mathrm{J} / \mathrm{kg}-\mathrm{K}$ & Greek Letter & \\
$g$ & Gravitational acceleration, $\mathrm{m} \mathrm{s}^{-2}$ & $\alpha$ & Thermal diffusivity, $\mathrm{m}^{2} / \mathrm{s}$ \\
$h$ & Heat transfer coefficient & $\beta$ & Thermal expansion coefficient, $\mathrm{K}^{-1}$ \\
$k$ & Thermal conductivity, $\mathrm{W} / \mathrm{m}-\mathrm{K}$ & $\mu$ & Viscosity, $\mathrm{kg} / \mathrm{m}-\mathrm{s}$ \\
$l$ & Height of inner square, $\mathrm{m}$ & $v$ & Kinematic viscosity, $\mathrm{m}^{2} / \mathrm{s}$ \\
$L$ & Height of outer square, $\mathrm{m}$ & $\theta$ & Dimensionless temperature \\
$N u$ & Nusselt number & $\rho$ & Density, $\mathrm{kg} / \mathrm{m}^{3}$ \\
$p$ & Pressure, $\mathrm{kg} / \mathrm{m} \mathrm{s}^{-2}$ & $\varphi$ & Volume fraction of nanoparticles \\
$P$ & Dimensionless pressure & & \\
$q$ & Heat flux & Subscript & \\
$P r$ & Prandtl number & avg & Average \\
$R a$ & Rayleigh number & $\mathrm{c}$ & Cold \\
$\mathrm{T}$ & Temperature, $\mathrm{K}$ & $f$ & Fluid \\
$u, v$ & Velocity component, $\mathrm{m} / \mathrm{s}$ & $\mathrm{h}$ & Hot \\
$U, V$ & Dimensionless velocity components & $n f$ & Nanofluid \\
$x, y$ & Cartesian coordinates, $\mathrm{m}$ & $s$ & particle \\
$\mathrm{X}, \mathrm{Y}$ & Dimensionless Cartesian coordinates & & \\
& & & \\
\hline
\end{tabular}
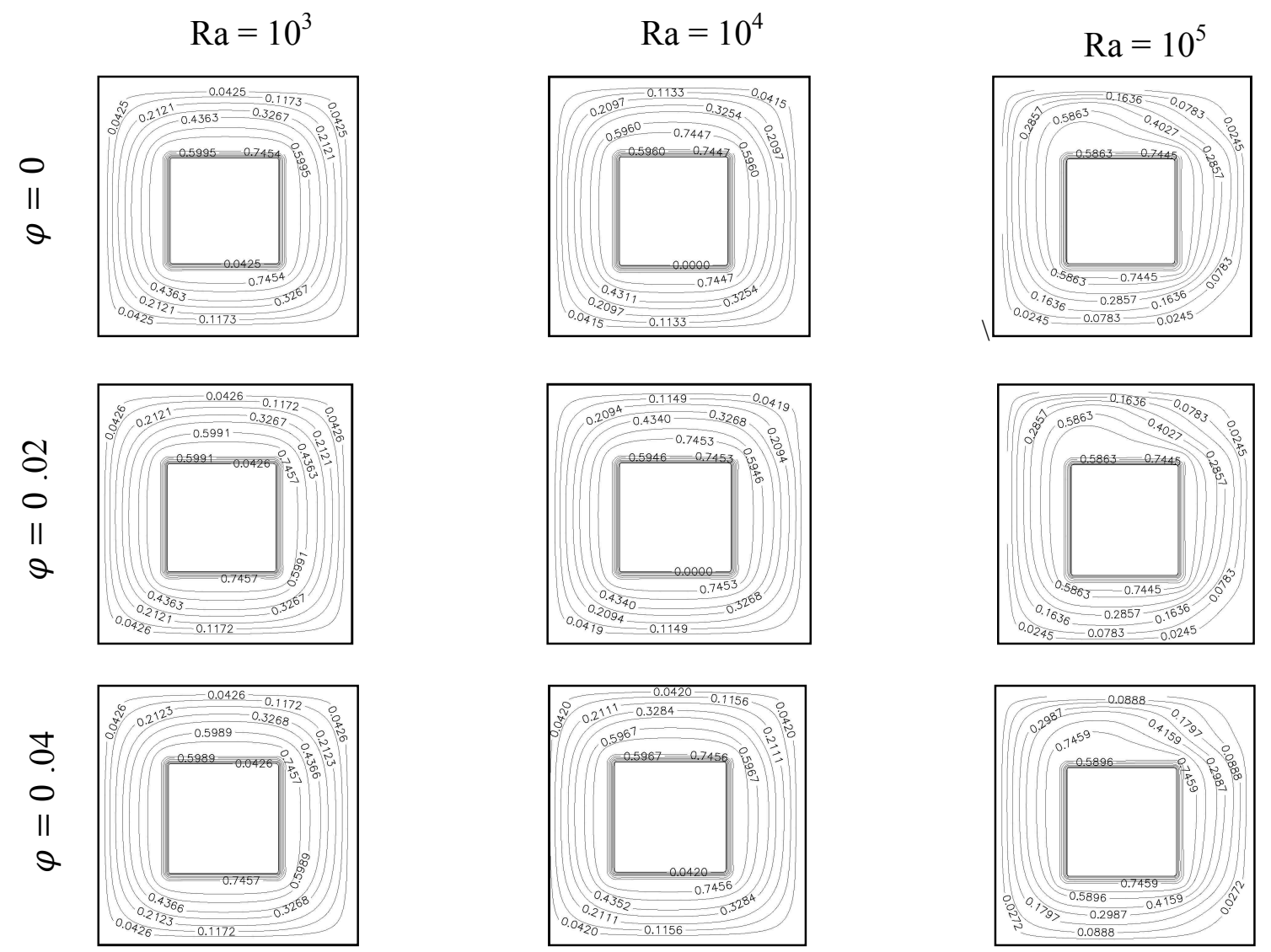

Figure 2: Isotherms in the space between concentric square filled with $\mathrm{TiO} 2$-water nanofluid for various nanoparticles volume fraction.

\section{References}

[1] S. Ostrach, Natural Convection in Enclosure, Journal of Heat Transfer 110 (1988) 1175-1190.

[2] S. Choi, Enhancing Thermal Conductivity of Fluids with Nanoparticles, ASME Fluids Engineering Division 231 (1995) 99-105.

[3] R. Nasrin, M. Alim, Free Convective Flow of Nanofluid Having Two Nanoparticles Inside a Complicated Cavity, International Journal of Heat and Mass Transfer 63 (2013) 191-198. 
[4] S. Das, S. Choi, H. Patel, Heat Transfer in Nanofluids - a Review, Heat Transfer Engineering 27 (2006): 3-19.

[5] S. Kakac, A. Pramuanjaroenkij, Review of Convective Heat Transfer Enhancement with Nanofluid, Int. J. Heat Mass Transfer 52:13-14 (2009) 3187-3196.

[6] K. Khanafer, K. Vafai, M. Lightstone, Buoyancy-driven Heat Transfer Enhancement in a Twodimensional Enclosure Utilizing Nanofluids, Int. J. Heat Mass Transfer 46 (2003) 3639-3653.

[7] R.Jou, S.Tzeng, Numerical Research of Nature Convective Heat Transfer Enhancement Filled with Nanofluids in Rectangular Enclosures, Int. Comm. Heat Mass Transfer 33 (2006) 727736.

[8] T. Basak, S. Roy, A.R. Balakrishnan, Effect of Thermal Boundary Conditions on Natural Convection Flow in a Square Cavity, Int. J. Heat Mass Transfer 49 (2006) 4525-4535.

[9] H. Oztop, E. Abu-Nada, Numerical Study of Natural Convection in Partially Heated Rectangular Enclosure Filled with Nanofluids, Int. J. Heat Fluid Flow 29 (2008) 1326-1336.

[10]G.A. Sheikhzadeh, A. Arefmanesh, M.H. Kheirkhah, R. Abdollahi, Natural Convection of Cuwater Nanofluid in a Cavity with Partially Active Side Walls, European Journal of MechanicsB Fluids 30 (2011) 166-176.

[11]E. Abu-Nada, H. Oztop, Effect of Inclination Angle on Natural Convection in Enclosure Filled with $\mathrm{Cu}$-water Nanofluid, International Journal of Heat and Fluid Flow 30 (2009) 669-678.

[12]E. Ogut, Natural Convection of Water-based Nanofluids in an Inclined Enclosure with a Heat Source, International Journal of Thermal Sciences 48 (2009) 2063-2073.

[13]R. Tiwari, M. Das, Heat Transfer Augmentation in a Two-sided Lid-driven Differently Heated Square Cavity Utilizing Nanofluids, International Journal of Heat and Mass Trans. 50 (2007) 2002-2018.

[14]E. Abu-Nada, Z. Masoud, H. Oztop, A. Campo, Effect of Nanofluid Variable Properties on Natural Convection in Enclosures, International Journal of Thermal Sciences 49 (2010) 479491.

[15]M. Mahmoodi, Numerical Simulation of Free Convection of a Nanofluid in L-shaped Cavities, International Journal of Thermal Sciences 50 (2011) 1731-1740.

[16]J.M. House, C. Beckermann, T.F. Smith, Effect of a Centered Conducting Body on Natural Convection Heat Transfer in an Enclosure, Num. Heat Trans., Part A 18: 2 (1990) 13-24.

[17]A. Kumar De, A. Dalal, A Numerical Study of Natural Convection Around a Square, Horizontal, Heated Cylinder Placed in an Enclosure, Int. J. Heat Mass Trans. 49 (2006) 46084623.

[18] S.M. Amonossadati, B. Ghasemi, Conjugate natural convection in an inclined nanofluid-filled enclosure, International Journal of Numerical Methods for Heat \& Fluid Flow, 22:4 (2012) 403-423.

[19]R. Roslan, H. Saleh, I. Hashim, Effect of Rotating Cylinder on Heat Transfer in a Square Enclosure Filled with Nanofluids, Int. J. Heat Mass Trans. 55 (2012) 7247-7256.

[20]R. Roslan, H. Saleh, I. Hashim, A.S. Bataineh, Natural Convection in an Enclosure Containing a Sinusoidally Heated Cylindrical Source, Int. J. Heat Mass Trans. 70 (2014) 119-127.

[21]M. Mahmoodi, S.M. Sebdani, Natural Convection in a Square Cavity Containing a Nanofluid and an Adiabatic Square Block at the Center, Superlattices and Microstructures 52 (2012) 261275.

[22]A. Arefmanesh, M. Amini, M. Mahmoodi, M. Najafi, Buoyancy-driven Heat Transfer Analysis in Two-Square Duct Annuli Filled with a Nanofluid, European Journal of Mechanics B/Fluids, 33 (2012) 95-104.

[23]A. Bejan, Convection Heat Transfer, Fourth ed., Wiley, United State of America, 2013. 